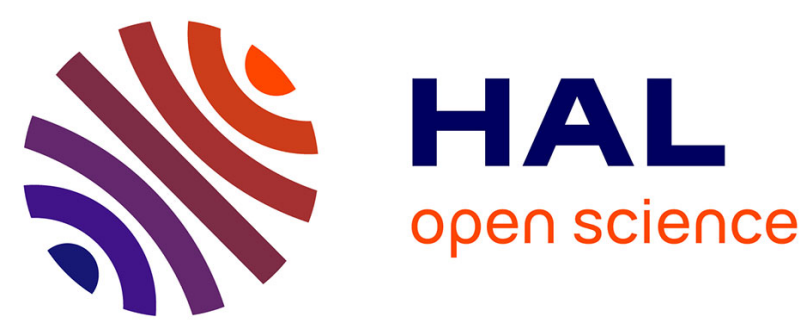

\title{
Microstructure characterization by X-ray tomography and EBSD of porous FeCr produced by liquid metal dealloying
}

Morgane Mokhtari, Christophe Le Bourlot, Jérôme Adrien, Anne Bonnin, Takeshi Wada, Jannick Duchet-Rumeau, Hidemi Kato, Eric Maire

\section{To cite this version:}

Morgane Mokhtari, Christophe Le Bourlot, Jérôme Adrien, Anne Bonnin, Takeshi Wada, et al.. Microstructure characterization by X-ray tomography and EBSD of porous $\mathrm{FeCr}$ produced by liquid metal dealloying. Materials Characterization, 2018, 144, pp.166-172. 10.1016/j.matchar.2018.06.032 . hal-01835520

\section{HAL Id: hal-01835520 \\ https://hal.science/hal-01835520}

Submitted on 3 Jan 2022

HAL is a multi-disciplinary open access archive for the deposit and dissemination of scientific research documents, whether they are published or not. The documents may come from teaching and research institutions in France or abroad, or from public or private research centers.
L'archive ouverte pluridisciplinaire HAL, est destinée au dépôt et à la diffusion de documents scientifiques de niveau recherche, publiés ou non, émanant des établissements d'enseignement et de recherche français ou étrangers, des laboratoires publics ou privés. 


\title{
Microstructure characterization by X-ray tomography and EBSD of porous FeCr produced by liquid metal dealloying
}

\author{
Morgane Mokhtari ${ }^{\mathrm{a}, \mathrm{b}, \mathrm{c}}$, Christophe Le Bourlot ${ }^{\mathrm{a}, *}$, Jérome Adrien $^{\mathrm{a}}$, Anne Bonnin ${ }^{\mathrm{d}}$, Takeshi Wada ${ }^{\mathrm{b}}$, \\ Jannick Duchet-Rumeau ${ }^{\mathrm{c}}$, Hidemi Kato ${ }^{\mathrm{b}}$, Eric Maire ${ }^{\mathrm{a}}$
}

${ }^{a}$ Univ Lyon, INSA Lyon, MATEIS, CNRS UMR5510, F-69621 Villeurbanne, France

${ }^{\mathrm{b}}$ Institute for Materials Research, Tohoku University, 2-1-1 Katahira, Aoba Ward, Sendai 980-8577, Japan

${ }^{\mathrm{c}}$ Univ Lyon, INSA Lyon, IMP, CNRS UMR5223, F-69621 Villeurbanne, France

d Swiss Light Source, Paul Scherrer Institute, Villigen, Switzerland

\section{A R T I C L E I N F O}

\section{Keywords:}

Dealloying

$\mathrm{X}$-ray tomography

EBSD

Porous

$\mathrm{Fe}$

\begin{abstract}
A B S T R A C T
Liquid metal dealloying is a promising technique to get nanoporous materials which are attractive for their excellent functional properties. From a $(\mathrm{FeCr})_{\mathrm{x}}-\mathrm{Ni}_{1-\mathrm{x}}$ precursor, it is possible to get porous $\mathrm{FeCr}$ with this technique.

While immersing precursors in a molten $\mathrm{Mg}$ bath, $\mathrm{Ni}$ atoms selectively migrate into the $\mathrm{Mg}$ bath. After cooling down to room temperature, the resulting microstructure is a bi-continuous structure of $\mathrm{FeCr}$ and $\mathrm{Mg}$ (with $\mathrm{Ni}$ in solid solution). A final etching step removes the Mg solid-state solution phase. Precursors with different compositions were dealloyed and imaged in 3D. From X-ray tomography images, porous FeCr characteristics as solid fraction, phase size, specific surface were extracted. EBSD maps were acquired on samples before and after dealloying.

We will show that precursor composition is a key parameter to control pores and grains size while dealloying parameters (time and temperature) are key parameters to control ligaments size and in fine specific surface. By controlling precursor composition and dealloying parameters it is now possible to get dealloyed nanoporous metals with desired grain and porous microstructure by liquid metal dealloying.
\end{abstract}

\section{Introduction}

Nanoporous metals have attracted considerable attention for their excellent functional properties including high catalytic activity, sensing capabilities and surface-enhanced Raman scattering [1-4]. Properties at the nanoscale differ significantly from those of their dense, bulky counterparts. Liquid metal dealloying is a promising technique to get nanoporous common materials. The liquid metal dealloying method is a selective dissolution phenomenon of a solid alloy precursor. One component (referred to as the soluble component) is soluble in the metallic melt while the other (referred to as the targeted component) is not. When the solid precursor is immersed in the metallic melt, only atoms of the soluble component dissolve into the melt inducing a spontaneously organized bi-continuous microstructure formed by the targeted and sacrificial phases (solidified metallic bath). After cooling down to room temperature, this sacrificial phase can be removed by selective chemical etching to obtain the final porous material with the targeted composition. It has enabled the preparation of micro/nanoporous structures of pure metals (Ti, Fe, Cr, Nb, Ta) [5-8], alloys (TiCrZr, TiZr, TiNb, TiHf, FeCr, NiCr) [6,9-11] and non-metals (Si, C) [12,13].

The study of the microstructure of these porous materials is not easy because it requires 3D information. The solid fraction morphology of porous $\mathrm{TiCrZr}$ and $\mathrm{NiCr}$ was already 3D imaged $[11,14]$. The dealloying mechanisms of Ta-Ti with different Ta/Ti ratio have been studied and a similar grain microstructure is observed before and after dealloying [8].

The mechanical, electrochemical properties of these porous materials are directly linked to their microstructure. The dealloying mechanism of FeCr-Ni was already studied in liquid and solid $\mathrm{Mg}$ bath $[6,15,16]$. Morphology of liquid metal dealloying resulting porous structure was mainly analyzed in 2D so far in the literature. In order to extract more information on porous structures, 3D analysis is available today and has been shown to be preferable. After a preliminary study on Titanium alloys [14], FeCr-Ni, the material of the present study, was observed by X-ray tomography in [17]. In this previous study however, the authors focused on short dealloying time with the evolution of pores and residual $\mathrm{Ni}$ at the early stage of dealloying. Contrarily to this 


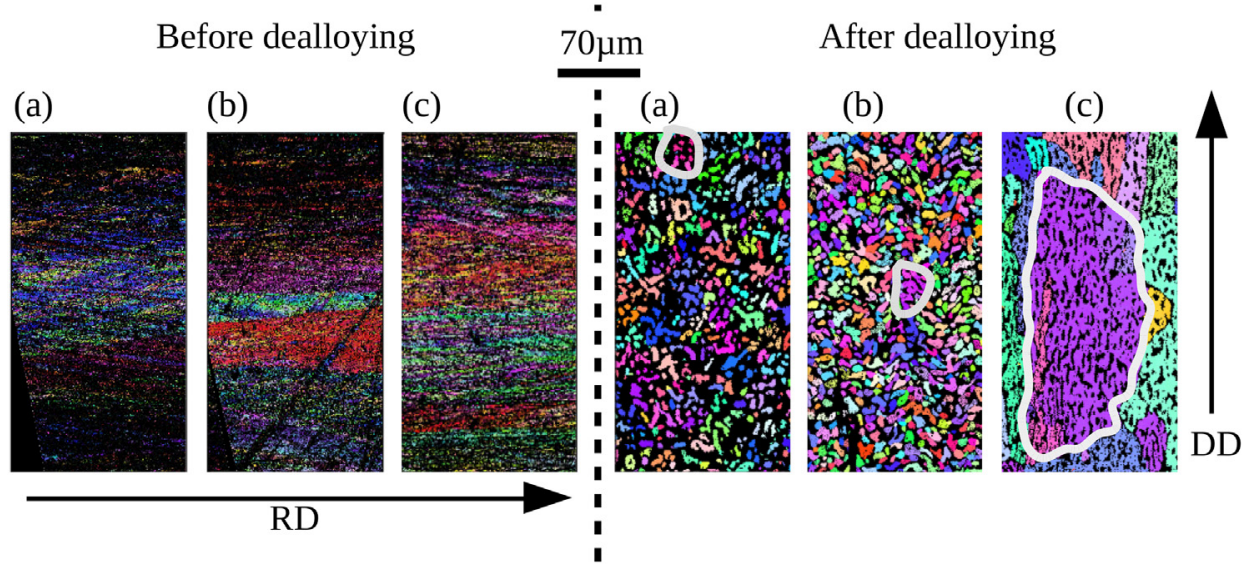

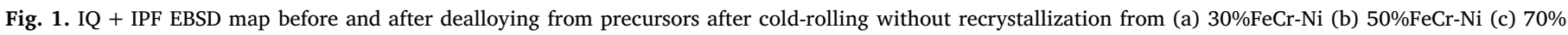
FeCr-Ni samples. Arrows correspond to cold-rolling direction (RD) and dealloying reaction direction (DD). White circle corresponds to one grain.

previous work, in the present study, we focus on long dealloying time. This enables us to have a coarsened structure with no residual sacrificial element inside the ligaments. In the present paper we also aim at analyzing the microstructure of the solid phase. In this respect, grain microstructure is very important to explain dealloying mechanisms and the resulting mechanical behavior. To study the grain microstructure, one of the most appropriate tools is EBSD (Electron BackScatter Diffraction) analysis. EBSD analysis on porous materials made by liquid metal dealloying has not been reported yet in the literature.

In the present paper EBSD was used to analyze grain microstructure before and after dealloying and X-ray tomography to image porous microstructure in 3D. The analysis for different precursor compositions was conducted to be able to predict sample microstructure and in fine sample properties.

\section{Materials and Methods}

A Fe-Cr-Ni alloy (the precursor) and a Mg molten bath were used in this work. The strategy for selecting precursor and molten bath element is described in [5]. $\left(\mathrm{Fe}_{80} \mathrm{Cr}_{20}\right)_{30} \mathrm{Ni}_{70}, \quad\left(\mathrm{Fe}_{80} \mathrm{Cr}_{20}\right)_{50} \mathrm{Ni}_{50}$ and $\left(\mathrm{Fe}_{80} \mathrm{Cr}_{20}\right)_{70} \mathrm{Ni}_{30}$ ingots were prepared using arc melting as described in [6]. The resulting precursors of around $1 \mathrm{~cm}$ thickness were cold-rolled until reaching the thickness of $1 \mathrm{~mm}$. For EBSD analysis one part of precursors were heat-treated $5 \mathrm{~h}$ at $1093 \mathrm{~K}$. For dealloying, cold-rolled precursors $1 \mathrm{~mm}$ thick sheets were directly cut without further heat treatment into $30 * 20 \mathrm{~mm}$ rectangular samples.

The dealloying step was carried out on these samples with a temperature of $1093 \mathrm{~K}$ for $1 \mathrm{~h}$ in a Mg melt bath under a high-purity He atmosphere to give $\mathrm{FeCr}-\mathrm{Mg}$ bicontinuous structure.

For EBSD precursor samples, cross sections were mechanically polished (the final step was performed using a colloid alumina solution). After dealloying, the cross sections were polished using an Ar ion beam polisher (EM-3500 Hitachi, Japan). The EBSD acquisitions were performed on JEOL 7100F (JEOL, Japan) and were analyzed with OIM analysis software.

For X-ray tomography imaging, samples were cut with a precision micro-cutting machine into a rectangular rod with $0.5-1 \mathrm{~mm}$ in sides and $1 \mathrm{~cm}$ in length and then polished into a tip shape. The selective etching step was carried out using highly concentrated nitric acid to dissolve the $\mathrm{Mg}$ based solid-state solution. This etching resulted in microporous $\mathrm{Fe}_{80} \mathrm{Cr}_{20}$.

To validate the use of laboratory X-ray source, X-ray tomography measurement were conducted both using synchrotron X-ray source on Tomcat beamline (SLS, PSI, Swiss) and using laboratory X-ray source on an easytom tomograph (RX Solutions, France). Acquisitions in Tomcat were done with an monochromatic source of $25 \mathrm{keV}$ and a voxel lateral isotropic size of $0.163 \mu \mathrm{m}$ and they were reconstructed in 32 bit floating point representation from $2 \mathrm{D}$ projections using optimized software based on Fourier methods using a Simultaneous phase and amplitude extraction ("paganin") [18-21]. Acquisition on an easytom tomograph were done using a polychromatic source operated at a voltage of $100 \mathrm{kV}$ and a voxel lateral isotropic size of $0.3 \mu \mathrm{m}$ and the reconstructions were obtained using the commercial software provided with the tomograph.

The reconstructions were analyzed with Fiji free software [22] on $90 \mu \mathrm{m}$ side cubes. All compositions were imaged and analyzed on both devices and quantitative analysis gave similar results for both tomographs. For the sake of conciseness, only results provided by easytom tomograph from $\left(\mathrm{Fe}_{80} \mathrm{Cr}_{20}\right)_{30} \mathrm{Ni}_{70},\left(\mathrm{Fe}_{80} \mathrm{Cr}_{20}\right)_{50} \mathrm{Ni}_{50}$ and $\left(\mathrm{Fe}_{80} \mathrm{Cr}_{20}\right)_{70} \mathrm{Ni}_{30}$ precursors and as comparison from $\left(\mathrm{Fe}_{80} \mathrm{Cr}_{20}\right)_{30} \mathrm{Ni}_{70}$ precursors imaged on Tomcat (referred to as $30 \% \mathrm{FeCr}-\mathrm{Ni}$ SLS and $30 \% \mathrm{FeCr}$ SLS for precursor and porous samples respectively) will be shown in Section 3.

$\left(\mathrm{Fe}_{80} \mathrm{Cr}_{20}\right)_{30} \mathrm{Ni}_{70},\left(\mathrm{Fe}_{80} \mathrm{Cr}_{20}\right)_{50} \mathrm{Ni}_{50}$ and $\left(\mathrm{Fe}_{80} \mathrm{Cr}_{20}\right)_{70} \mathrm{Ni}_{30}$ precursors will be referred to as $30 \% \mathrm{FeCr}-\mathrm{Ni}, 50 \% \mathrm{FeCr}-\mathrm{Ni}$, $70 \% \mathrm{FeCr}-\mathrm{Ni}$ respectively. After dealloying, porous samples obtained from $\left(\mathrm{Fe}_{80} \mathrm{Cr}_{20}\right)_{30} \mathrm{Ni}_{70},\left(\mathrm{Fe}_{80} \mathrm{Cr}_{20}\right)_{50} \mathrm{Ni}_{50}$ and $\left(\mathrm{Fe}_{80} \mathrm{Cr}_{20}\right)_{70} \mathrm{Ni}_{30}$ precursors will be referred to as $30 \% \mathrm{FeCr}, 50 \% \mathrm{FeCr}$ and $70 \% \mathrm{FeCr}$ respectively.

\section{Results and Discussion}

\subsection{Grain Microstructure Characterization}

\subsubsection{Cold-rolled Samples}

In this part the EBSD maps on precursor samples were acquired directly after cold-rolling without recrystallization. Fig. 1 presents the grain microstructure before and after dealloying with Index Quality (IQ) + Inverse Pole Figure (IPF) maps. Before dealloying the microstructure is highly affected by cold-rolling: grains are elongated along the cold-rolling direction and the degree of indexation is low: most of the maps are black i.e. non-indexed. This result is similar to others coldrolled samples [23-25]. The influence of the composition of precursor samples on EBSD map is not evident. Precursor samples present only FCC phase while after dealloying samples present only BCC phase [16]. After dealloying $30 \% \mathrm{FeCr}$ and $50 \% \mathrm{FeCr}$ present small randomly oriented grains composed of a small number of ligaments while $70 \% \mathrm{FeCr}$ presents large grains, each grain including many ligaments of similar orientation.

From phase diagrams, $30 \% \mathrm{FeCr}-\mathrm{Ni}$ and $50 \% \mathrm{FeCr}-\mathrm{Ni}$ should be FCC phase at room and dealloying temperature without allotropic transformation between both. However $70 \% \mathrm{FeCr}-\mathrm{Ni}$ should be composed of both FCC (main) and BCC phase at room temperature [26,27]. At higher temperature (over $673 \mathrm{~K}$ ) $70 \% \mathrm{FeCr}-\mathrm{Ni}$ is composed of only FCC phase [28]. Because of low inter-diffusion coefficient between Fe and 
Table 1

Comparison between grain size given by the software and measured on the map. For 30 and $50 \%$ samples, the software actually measures the ligament size.

\begin{tabular}{lll}
\hline Grain size $(\mu \mathrm{m})$ & Software & Images \\
\hline $30 \% \mathrm{FeCr}$ & $6.4 \pm 0.6$ & $37 \pm 17$ \\
$50 \% \mathrm{FeCr}$ & $8.0 \pm 3.0$ & $28 \pm 5$ \\
$70 \% \mathrm{FeCr}$ & $105 \pm 5$ & $125 \pm 8$ \\
\hline
\end{tabular}

$\mathrm{Ni}$, it is probably more difficult to reach equilibrium at low temperature. This is a good explanation why BCC phase could not be observed [29]. From phase diagrams again [26,30], $\mathrm{Fe}_{80} \mathrm{Cr}_{20}$ is composed of $\mathrm{BCC}$ phase, in agreement with our EBSD analysis.

Table 1 presents the average grain size measured by two methods (i) given by OIM analysis software where grain are assimilated to circle (ii) calculated from the average of six manual measurements on the EBSD map. One grain for each map after dealloying is circled in white in Fig. 1 to highlight what we considered as a grain in this manual measurement. We can see when the amount of solid increases in the porous sample, the difference between the two methods decreases. In fact, for $30 \% \mathrm{FeCr}$, the measurement given by the software corresponds to ligaments size and not grain size because the analysis is done in 2D and the connection between ligaments is not obvious while for $70 \% \mathrm{FeCr}$ even in 2D the connection between ligaments is present: OIM analysis software could capture the full porous grain.

Before dealloying grains are highly affected by cold-rolling. Because dealloying is performed at high temperature, we can expect a recrystallization of the precursor sample prior or during dealloying. The difference between $30 \% / 50 \% \mathrm{FeCr}-\mathrm{Ni}$ and $70 \% \mathrm{FeCr}-\mathrm{Ni}$ could be explained by different recrystallization rate or/and dealloying rate. This material $(70 \% \mathrm{FeCr}-\mathrm{Ni})$, could indeed have time to fully recrystallize before dealloying while for the two other ones $(30 \% / 50 \% \mathrm{FeCr}-\mathrm{Ni})$, recrystallization could be slower.

\subsubsection{After Recrystallization}

In this part, cold rolled precursor samples were subsequently recrystallized $5 \mathrm{~h}$ at $1093 \mathrm{~K}$ under highly vacuumed atmosphere and then air quenched. Fig. 2 presents the grain microstructure before and after dealloying with Index Quality (IQ) + Inverse Pole Figure (IPF) maps. After recrystallization, grains exhibit a rather polygonal shape with an average diameter of around $25 \mu \mathrm{m}$ which are typical for recrystallized austenite [31-33]. Before dealloying the effect of the composition on the microstructure is not strong. Samples also present only a FCC structure. After dealloying, only BCC phase is presented. $30 \% \mathrm{FeCr}$ and $50 \% \mathrm{FeCr}$ presents small grains composed of a couple of ligaments which look randomly oriented while $70 \% \mathrm{FeCr}$ presents large grains including many ligaments. This result is different compared to previous studies where no microstructure change was observed between precursor and dealloyed samples [8,34,35]. In our case however, dealloying occurs at high temperature and phase transformation occurs between precursor and dealloyed samples. Precursor shape was almost preserved during dealloying and shrinkage was almost not noticed after dealloying for all samples, with no influence of the recrystallization step. This makes a difference compared to the dealloying of cold-rolled Au-Pd-Ag sheets where a large shrinkage was observed [36]. This difference between our results and the ones from chemical dealloying can be explained by the very low targeted element amount (5 at.\% $\mathrm{Au}$ in precursor). Moreover liquid metal dealloying is done at high temperature, which plays a similar role than heat treatment on the microstructure.

While comparing Figs. 1 and 2 after dealloying, no significant difference is observed. This means that the different behavior between $30 \% / 50 \% \mathrm{FeCr}$ and $70 \% \mathrm{FeCr}$ could not be explained by the absence of recrystallization treatment after cold-rolling step. To explain this difference, another hypothesis can be postulated: if one considers the same interface precursor/dealloyed sample, when the amount of $\mathrm{FeCr}$ is low, $\mathrm{Fe}$ and $\mathrm{Cr}$ can be considered as spatially isolated. Moreover for low $\mathrm{FeCr}$ amount in precursor, dealloying front rate is high and this promotes diffusion and displacive transformation. As a consequence, nucleation of new grains is easy and grain size is rather small. On the contrary when the amount of $\mathrm{FeCr}$ is high and the dealloying rate low (controlled by the $\mathrm{Ni}$ diffusion rate in the solid phase), a diffusive phase transformation is observed (Fig. 2c) with large grains due to grain growth rather than nucleation of new grains [37]. So the difference of behavior could be partly explained by this competition between crystal nucleation and crystal growth. For 30/50\% FeCr-Ni samples, nucleation would be the dominant mechanism while for $70 \% \mathrm{FeCr}-\mathrm{Ni}$ sample, that would be grains growth.

\subsection{Morphology Characterization}

\subsubsection{Qualitative Analysis}

Fig. 3 shows one reconstructed slice for each sample extracted from the reconstruction. Two phases are visible. The lighter phase corresponds to the FeCr phase and the darker phase to the air. The amount of white phase is qualitatively coherent with the samples expected composition. Fig. 3a obtained using the synchrotron tomograph seems to have similar $\mathrm{FeCr}$ volume fraction and ligaments size to Fig. $3 \mathrm{~b}$ ones (same type of sample but scanned using our laboratory tomograph). In the case of the synchrotron image, the contrast is better.

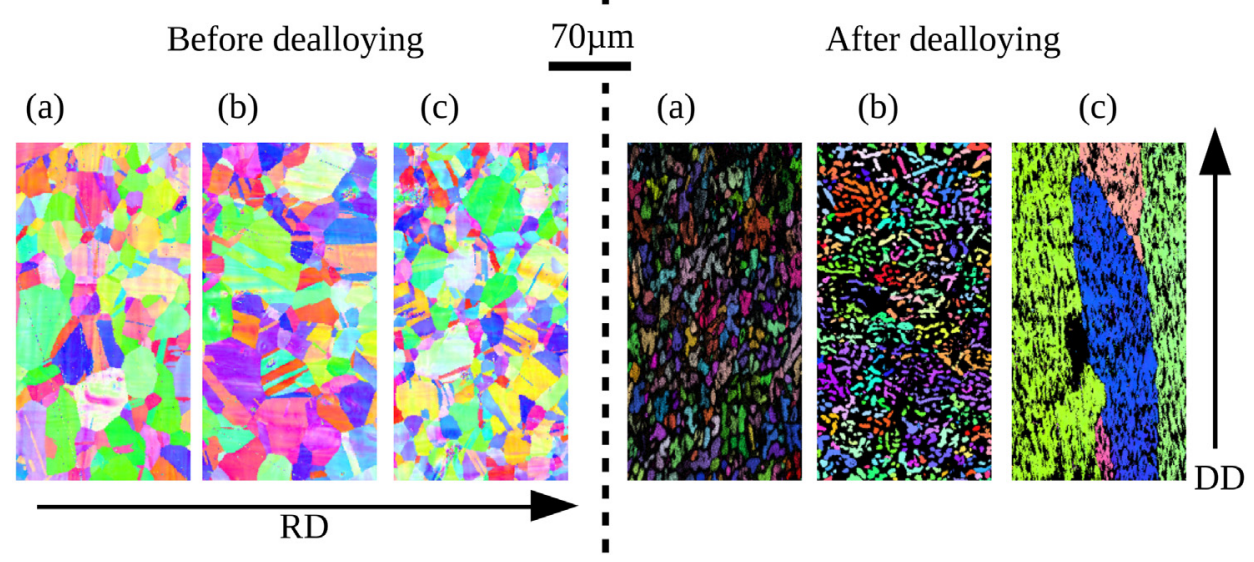

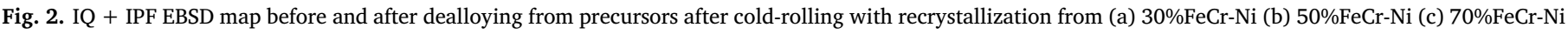
samples. Arrows correspond to cold-rolling direction (RD) and dealloying reaction direction (DD). 
(a)

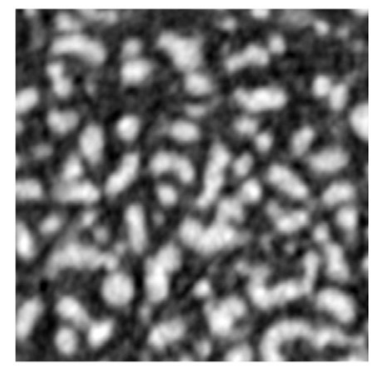

(b)

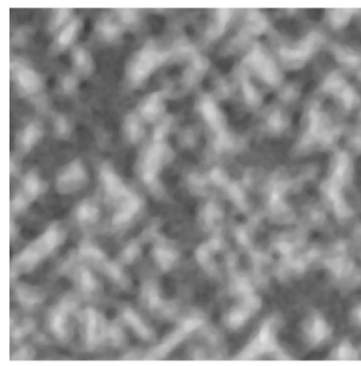

(c)

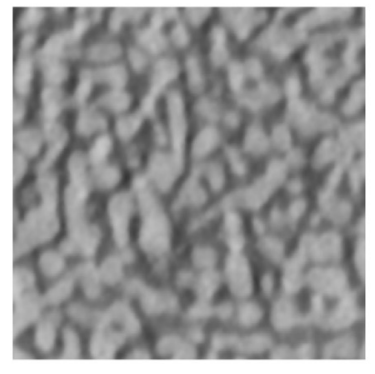

(d)

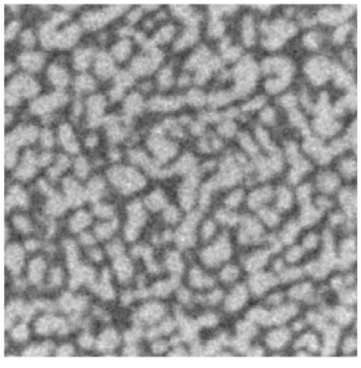

$20 \mu \mathrm{m}$

Fig. 3. Images extracted from X-ray tomography scan of (a) SLS $30 \% \mathrm{FeCr}$ (b) $30 \% \mathrm{FeCr}$ (c) $50 \% \mathrm{FeCr}$ (d) $70 \% \mathrm{FeCr}$.

Table 2

Morphological samples parameters.

\begin{tabular}{|c|c|c|c|c|}
\hline & SLS $30 \% \mathrm{FeCr}$ & $30 \% \mathrm{FeCr}$ & $50 \% \mathrm{FeCr}$ & $70 \% \mathrm{FeCr}$ \\
\hline Volume fraction (vol\%) & $0.31 \pm 0.03$ & $0.28 \pm 0.03$ & $0.46 \pm 0.03$ & $0.68 \pm 0.03$ \\
\hline Average ligaments size $(\mu \mathrm{m})$ & $5.0 \pm 1.5$ & $4.5 \pm 1.3$ & $5.0 \pm 1.2$ & $4.8 \pm 1.6$ \\
\hline Average pore size $(\mu \mathrm{m})$ & $6.2 \pm 2.0$ & $6.5 \pm 2.2$ & $4.1 \pm 1.2$ & $3.0 \pm 0.6$ \\
\hline Connectivity $\mathrm{FeCr} / \mathrm{air}( \pm 0.0002)$ & $1.0000 / 1.0000$ & $1.0000 / 1.0000$ & $1.0000 / 1.0000$ & $1.0000 / 1.0000$ \\
\hline Genus $( \pm 100)$ & $4.10^{2}$ & $5.10^{2}$ & $13.10^{2}$ & $32.10^{2}$ \\
\hline Scaled genus $( \pm 0.02)$ & 0.02 & 0.02 & 0.03 & 0.06 \\
\hline Specific surface $\left(\mathrm{m}^{2} / \mathrm{kg}\right)$ & $121 \pm 4$ & $138 \pm 4$ & $109 \pm 3$ & $79 \pm 2$ \\
\hline Specific surface $\left(\mathrm{m}^{2} / \mathrm{m}^{3}\right)$ & $(3.1 \pm 0.2) \cdot 10^{5}$ & $(3.0 \pm 0.2) \cdot 10^{5}$ & $(3.8 \pm 0.2) \cdot 10^{5}$ & $(4.1 \pm 0.2) \cdot 10^{5}$ \\
\hline Tortuosity FeCr/air $( \pm 0.2)$ & $1.1 / 1.6$ & $1.2 / 1.3$ & $1.1 / 1.4$ & $1.2 / 1.2$ \\
\hline
\end{tabular}

\subsubsection{Quantitative Analysis}

Volume was filtrated with a bilateral filter plugin added in Fiji. The intensity curve with gray level presents two peaks (one for each phase) and the threshold value was chosen between these two peaks.

Table 2 summarizes an inventory of all parameters measured from $\mathrm{X}$-ray tomography images. Ligaments/pores size and connectivity were measured with Fiji function/plugin "local thickness" and "find connected area" [22,38,39]. Volume fraction, specific surface and tortuosity were measured with homemade plugins described in [40]. Euler number was measured with Morpholibj plugin [41].

The value of porous FeCr volume fraction is close to the one expected from the $\mathrm{FeCr} / \mathrm{Ni}$ atomic fraction of the precursor. During the dealloying reaction, $\mathrm{Ni}$ atoms are removed from the $\mathrm{FeCr}$-Ni lattice and the remaining $\mathrm{FeCr}$ atoms reconstruct a $\mathrm{FeCr}$ lattice. According to the reported lattice parameter of $\mathrm{FeCr}-\mathrm{Ni}$ and $\mathrm{FeCr}$, the volume of the unit cell divided by the number of atoms, the theoretical $\mathrm{FeCr}$ volume fraction divided by precursor atomic fraction is 1.03. The experimental results are in good agreement with this predicted value [42-45].

Fig. 4 (left) presents the phase thickness distribution of FeCr and Air phases for all samples. As already mentioned in literature for a similar process, phases display an unimodal and somewhat scattered thickness distribution $[11,14,46]$. In Table 2, the average phase thickness of both phases is reported. We can firstly notice that even if resolution and contrast were higher with SLS facilities, there is no incidence on our phase distribution. This means that even if the lab tomography shows a poorer contrast, segmenting our both phases correctly was still possible. Remarkably, $\mathrm{FeCr}$ phase thickness distributions are similar for all samples. This clearly shows that in our case, ligaments size are independent of precursor composition, it was also noticed in ref. [17]. Because $\mathrm{FeCr}$ phase thickness distributions are similar and materials densities are different, pore distributions must on the contrary be dependent on the composition of the precursor. If we assimilate our structure to a perfect alternation of ligaments and pores, the pore size divided by ligament size is equal to pore fraction divided by $\mathrm{FeCr}$ fraction. We calculated the theoretical pore/ligament size for various $\mathrm{FeCr}$ amount. Then, we plotted our experimental values and the theoretical ones in Fig. 4 (right). Our experimental values match fairly well the theoretical ones. This allows us to validate a rule for controlling pore size by simply tailoring the composition, time and temperature of dealloying.

The average ligament size is $4.8 \pm 0.3 \mu \mathrm{m}$ for $1 \mathrm{~h}$ dealloying at $1093 \mathrm{~K}$. In ref. [6], $\mathrm{Fe}_{30} \mathrm{Ni}_{70}$ precursors were dealloyed in similar
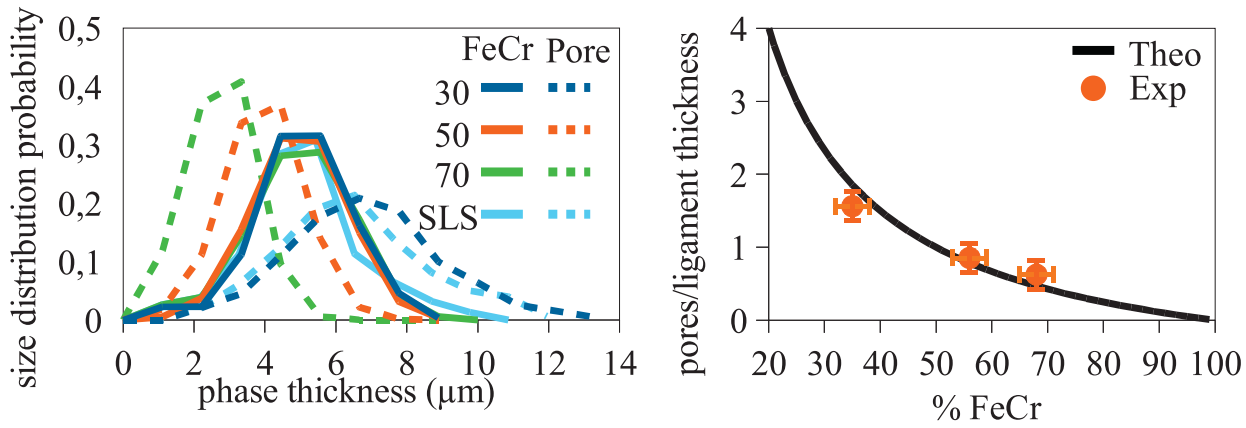

Fig. 4. Evolution of phase thickness for different volume fraction (left) and evolution of pores/ligaments size ration with volume fraction (right). 
conditions to our study so some of their result can be extrapolated. Fig. $3 \mathrm{~b}$ in their paper shows the evolution of the ligament size (measured by SEM), for different dealloying times. By using Eq. (3) of this paper for the time and temperature used in our study, the expected ligament size is $5.08 \mu \mathrm{m}$ [6]. This is very close to what we have measured in Table 2. Similar ligament size for different precursor compositions suggests similar activation energy. This series of results shows that the addition of $\mathrm{Cr}$ has a limited influence on the coarsening behavior.

One of the main interests of microporous materials is their large specific surface area. Specific surface in $\left(\mathrm{m}^{2} / \mathrm{kg}\right)$ and $\left(\mathrm{m}^{2} / \mathrm{m}^{3}\right)$ are displayed in Table 2. For different compositions, specific surface is different while ligaments size is constant. This means that the specific surface depends on sample density. These values of specific surface are comparable to porous $\mathrm{NiCr}$ obtained with the same methods [11] but very low compared to nanoporous gold obtained by dealloying in aqueous solution [47]. In the present study, our samples, were not particularly designed to get very small ligaments. However if necessary, ligament size can be easily decreased for example by using solid state inter-facial dealloying reaction (reported ligament size down to $400 \mathrm{~nm}$ in [6]) or even liquid metal dealloying at lower temperature and shorter dealloying time (reported ligament size down to $650 \mathrm{~nm}$ in [15]).

Detsi et al. linked the specific surface area $(S)$ with the porous sample's characteristics: ligament size (d), bulk density $(\rho)$ and a constant C in Eq. (1) [48].

$S=\frac{C}{\rho * d}$

Specific surface $v s$ B is plotted in Fig. 5a. Graphically, the value of C constant can be extracted. We measure $C=3.7 \pm 0.4$. Values reported in the literature for nanoporous gold is $\mathrm{C}=3.7$ and $\mathrm{C}=3.4$ for the simulation of single gyroid nanostructure [47-49]. This clearly shows that the structure of our materials is close to single gyroid structure. Finding a similar $\mathrm{C}$ for nanoporous gold and our material shows one more similarity in the structure of materials elaborated by different dealloying processes. Eq. (1) is therefore validated for our material and can thus be used to calculate the suitable ligament size for a given specific surface.

For various applications where the transport of electrical charges is a key property (such as capacitors), it is important to have a perfectly connected structure and a high specific surface [1-4]. Connectivity of both phases for all samples is equal to 1 . This value validates the fact that our materials exhibit a bi-continuous structure. The connectivity value is a good way to measure if the structure is perfectly connected or not. Euler characteristic and genus are also often used for this purpose [50-53]. Genus is calculated as (Euler number $/ 2+1$ ) and corresponds to the number of connections inside the structure [51-53]. We measured respectively around 500, 1300 and 3000 connections for $30 \%$
FeCr, $50 \% \mathrm{FeCr}$ and $70 \% \mathrm{FeCr}$. As expected, the number of connections increases with the amount of solid phase in the sample. However the genus of $70 \% \mathrm{FeCr}$ is 6 times higher than the one of $30 \% \mathrm{FeCr}$ whereas the ratio of the amount of solid phase is only 2.3. This means that $70 \%$ $\mathrm{FeCr}$ is better connected than $30 \% \mathrm{FeCr}$. Dividing the genus per unit volume with the cube of the specific area provides a dimensionless genus called scaled genus. Our scaled genus (0.02 to 0.06) is comparable with the one's found for nanoporous gold (from 0.0015 to 0.147 ) [51-53].

Transport properties, diffusivity and conductivity properties are depending on tortuosity. The effective conductivity $\left(\mathrm{C}_{\text {eff }}\right)$ and diffusivity $\left(D_{\text {eff }}\right)$ are linked with the intrinsic conductivity $\left(C_{i}\right)$ and diffusivity $\left(D_{i}\right)$, the tortuosity $(\tau)$ and the phase fraction of the conductive phase (p) in respectively Eqs. (2) and (3) [54]

$C_{\text {eff }}=\frac{C_{i} * p}{\tau}$

$D_{\text {eff }}=\frac{D_{i} * p}{\tau}$

The tortuosity $(\tau)$ is a factor only depending on the porous sample's geometry. Tortuosity of both phases can be found in Table 2. Tortuosity is defined by the ratio of the length of the curve to the Euclidian distance between the ends of the curve. A tortuosity equal to one corresponds to pores parallel to the transport direction as for example honey comb cells. A tortuosity included between one and three means than the transports properties are lower than the intrinsic transport properties of the conductive phase and also relatively good connectivity and low meandering of the pores [55]. A tortuosity equal to 3 corresponds to an isotropic spatial distribution of the pores [56]. In our case, bicontinuous structure does not enable to have isotropic pores/matters so this is consistent with a tortuosity below 3 . All the values that we measure for $\tau$ are rather small, between 1 and 1.3. The low tortuosity of our materials suggests from Eqs. (2) and (3) that the material should exhibit good diffusion and transport properties compared to materials with higher tortuosity. Our tortuosity is comparable to the one of microporous TiCrZr obtained by liquid metal dealloying [14].

In 1935 , the volume fraction ( $\rho$ ) and the tortuosity was linked by [57] in Eq. (4) where $\gamma$ and a are constant depending on the morphology, porosity, material, and particle-size distribution of the material. Usually people take $\gamma=1$ and adjust $\mathrm{a}$, or $\mathrm{a}=1.5$ and adjust $\gamma$. The simplest case corresponds to $\gamma=1$ and $\mathrm{a}=1.5[14,54]$

$\tau^{2}=\gamma^{*} \rho^{1-a}$

Fig. $5 \mathrm{~b}$ corresponds to the plot of Eq. (2). Our value shows almost a good agreement with Bruggeman law. Fig. $5 c$ corresponds to the air phase tortuosity value of $70 \% \mathrm{FeCr}$. White points correspond to the highest tortuosity measure (around 2.2) and dark blue to the lowest (1). (a)

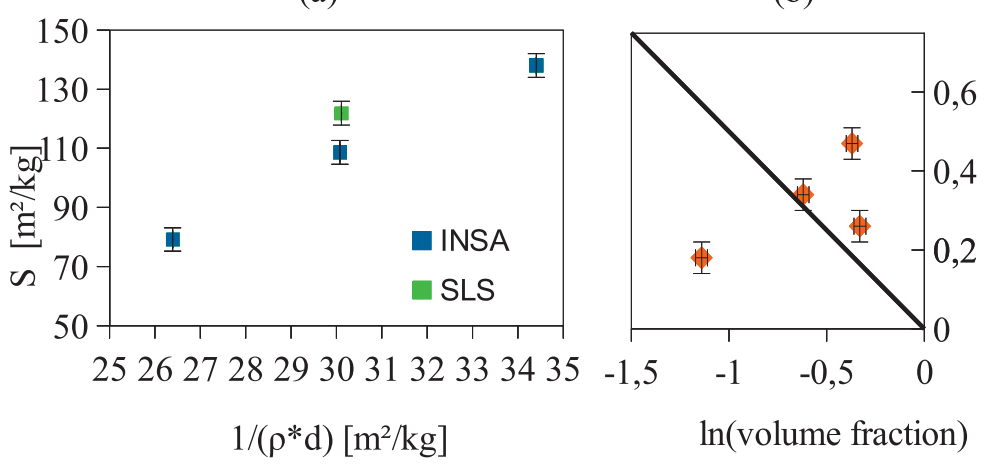

(c)

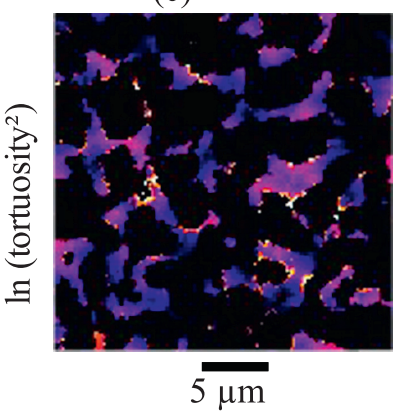

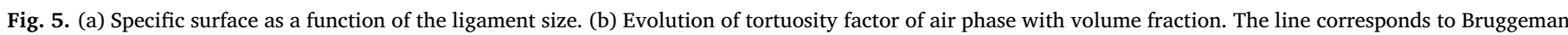

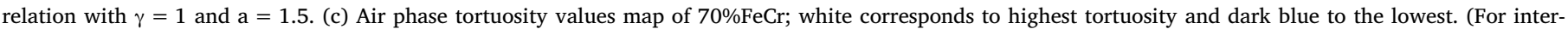
pretation of the references to color in this figure legend, the reader is referred to the web version of this article.) 
Except some small areas (around 2 vol\%) with a higher tortuosity, tortuosity is small.

\section{Conclusion}

From $(\mathrm{FeCr})_{\mathrm{x}}-\mathrm{Ni}_{1-\mathrm{x}}$ with $\mathrm{x}=30,50$ and 70 precursors were dealloyed $1 \mathrm{~h}$ at $1093 \mathrm{~K}$ in $\mathrm{Mg}$ melt. EBSD maps were acquired on samples before and after dealloying. A phase transformation happened during the dealloying process: precursors samples were FCC phase while dealloyed samples were BCC phase. Different behavior were observed depending on precursor composition: 30 and $50 \% \mathrm{FeCr}$ present small grains while $70 \% \mathrm{FeCr}$ presents large grains resulting in different grain formation mechanisms. Etched samples were 3D imaged by Lab and synchrotron X-ray tomography. Porous sample morphological parameters were extracted and similar results were given by both Lab and synchrotron tomography. From our analysis porous sample morphological characteristics can be extracted: volume fraction is directly linked to precursor composition. Dealloying time and temperature control the ligaments size while precursor composition controls the pore size. Specific surface is linked to ligament size by a well-known equation and suitable specific surface can be obtained calculating the dealloying time and temperature. Specific surface area of porous $\mathrm{FeCr}$ is very close to the one of single gyroid microstructure. Our tortuosity and connectivity are close to 1 and independent of the volume fraction. This proves the presence of a bicontinuous structure and shall lead to good transport properties.

Precursor composition is a key parameter to control pore and grain size while dealloying parameters (time and temperature) are key parameters to control ligament size and in fine specific surface. In conclusion, this study shows how to design porous $\mathrm{FeCr}$ with desired grain size and morphology.

\section{Acknowledgement}

This work was supported by Région Rhone-Alpes [CMIRA 138249], Erasmus + program and the French Ministry of Higher Education and Research.

\section{References}

[1] J. Erlebacher, R. Seshadri, Hard materials with tunable porosity, MRS Bull. 34 (2009) 561-568.

[2] J. Snyder, T. Fujita, M. Chen, J. Erlebacher, Oxygen reduction in nanoporous metal-ionic liquid composite electrocatalysts, Nat. Mater. 9 (2010) 904-907.

[3] X.Y. Lang, A. Hirata, T. Fujita, M. Chen, Nanoporous metal/oxide hybrid electrodes for electrochemical supercapacitors, Nat. Nanotechnol. 6 (2011) 232-236.

[4] L.Y. Chen, J.S. Yu, T. Fujita, M. Chen, Nanoporous copper with tunable nanoporosity for SERS applications, Adv. Funct. Mater. 19 (2009) 1221-1226.

[5] T. Wada, K. Yubuta, A. Inoue, H. Kato, Dealloying by metallic melt, Mater. Lett. 65 (2011) 1076-1078.

[6] T. Wada, H. Kato, Three-dimensional open-cell macroporous iron, chromium and ferritic stainless steel, Scr. Mater. 68 (2013) 723-726.

[7] J.W. Kim, T. Wada, S.G. Kim, H. Kato, Sub-micron porous niobium solid electrolytic capacitor prepared by dealloying in a metallic melt, Mater. Lett. 116 (2014) 223-226.

[8] I. McCue, B. Gaskey, P.-A. Geslin, A. Karma, J. Erlebacher, Kinetics and morphological evolution of liquid metal dealloying, Acta Mater. 115 (2016) 10-23.

[9] I.V. Okulov, J. Weissmüller, J. Markmann, Dealloying-based interpenetrating-phase nanocomposites matching the elastic behavior of human bone, Sci. Rep. 7 (2017) 20.

[10] A.V. Okulov, A.S. Volegov, J. Weissmüller, J. Markmann, I.V. Okulov, Dealloyingbased metal-polymer composites for biomedical applications, Scr. Mater. 146 (2018) 290-294.

[11] M. Mokhtari, C. Le Bourlot, J. Adrien, S. Dancette, T. Wada, J. Duchet-Rumeau, H. Kato, E. Maire, Cold-rolling influence on microstructure and mechanical properties of NiCr-Ag composites and porous NiCr obtained by liquid metal dealloying, J. Alloys Compd. 707 (2017) 251-256.

[12] T. Wada, T. Ichitsubo, K. Yubuta, H. Segawa, H. Yoshida, H. Kato, Bulk-nanoporoussilicon negative electrode with extremely high cyclability for lithium-ion batteries prepared using a top-down process, Nano Lett. 14 (8) (2014) 4505-4510.

[13] S.G. Yu, K. Yubuta, T. Wada, H. Kato, Three-dimensional bicontinuous porous graphite gerenated in low teperature metallic melt, Carbon 96 (2016) 403-410.

[14] Y.-C.K. Chen-Wiegart, T. Wada, N. Butakov, X. Xiao, F. De Carlo, H. Kato, J. Wang,
D.C. Dunand, E. Maire, 3D morphological evolution of porous titanium by x-ray micro- and nano-tomography, J. Mater. Res. 28 (2013) 2444-2452.

[15] T. Wada, K. Yubuta, H. Kato, Evolution of a bicontinuous nanostructure via a solidstate interfacial dealloying reaction, Scr. Mater. 118 (2016) 33-36.

[16] T. Wada, P.-A. Geslin, H. Kato, Preparation of hierarchical porous metals by twostep liquid metal dealloying, Scr. Mater. 142 (2018) 101-105.

[17] Z. Chonghang, T. Wada, V. De Andrade, G.J. Williams, J. Gelb, L. Li, J. Thieme, H. Kato, Y.K. Chen-Wiegart, Three-dimensional morphological and chemical evolution of nanoporous stainless steel by liquid metal Dealloying, ACS Appl. Mater. Interfaces 9 (39) (2017) 34172-34184.

[18] C. Hintermüller, F. Marone, A. Isenegger, M. Stampanoni, Image processing pipeline for synchrotron-radiation-based tomographic microscopy, J. Synchrotron Radiat. 17 (2010) 550-559.

[19] F. Marone, B. Münch, M. Stampanoni, Fast reconstruction algorithm dealing with tomography artifacts, Proc. SPIE 7804, Dev. X-ray Tomogr. VII, 2010 (780410).

[20] F. Marone, M. Stampanoni, Regridding reconstruction algorithm for real time tomographic imaging, J. Synchrotron Radiat. 19 (2012) 1029-1037.

[21] D. Paganin, S.C. Mayo, T.E. Gureyev, P.R. Miller, S.W. Wilkins, Simultaneous phase and amplitude extraction from a single defocused image of a homogeneous object, J. Microsc. 206 (2002) 33-40.

[22] J. Schindelin, I. Arganda-Carreras, E. Frise, et al., Fiji: an open-source platform for biological-image analysis, Nat. Methods 9 (2012) 676-682.

[23] N. Barekar, S. Das, Z. Fan, R. Cindery, N. Champion, Microstructural evaluation during melt conditioned twin roll casting (MC-TRC) of Al-Mg, Mater. Sci. Forum 790 (2014) 285-290.

[24] S. Suwas, R.K. Ray, Crystallographic Texture of Materials, Springer-Verlag London, 2014.

[25] X. Zhao, Y. Shen, L. Qiu, Y. Liu, X. Sun, L. Zuo, Effects of intercritical annealing temperature on mechanical properties of Fe-7.9Mn-0.14Si-0.05Al-0.07C steel, Materials 7 (12) (2014) 7891-7906.

[26] J.S. Marsh, Limits of new phase in the Fe-Cr-Ni system, Met. Prog. 35 (1939) 269-272.

[27] F.H. Hayes, M.G. Hetherington, R.D. Longbottom, Thermodynamics of stainless steels, Mater. Sci. Technol. 6 (1990) 263-272.

[28] J.W. Pugh, J.D. Nisbet, Iron-chromium-nickel ternary system, Trans. AIME 188 (1950) 268-276.

[29] G. Cacciamani, A. Dinsdale, M. Palumbo, A. Pasturel, The Fe-Ni system: thermodynamic modelling assisted by atomistic calculations, Intermetallics 18 (6) (2010) 1148-1162.

[30] T.B. Massalski, H. Okamoto, P.R. Subramanian, L. Kacprzak, Fe-Cr phase diagram, Binary Alloy Phase Diagrams, vol. 2, ASMI, 1990, p. 1273.

[31] H.R. Abedi, A. Zarei Hanzaki, Z. Liu, R. Xin, N. Haghdadi, P.D. Hodgson, Continuous dynamic recrystallization in low density steel, Mater. Des. 114( (2017) 55-64.

[32] S. Qin, H. Zhang, J. Liu, W. Zhengi, Electron backscattered diffraction analysis of the effect of deformation temperature on the microstructure evolution in a typical nickel-based superalloy during hot deformation, J. Mater. Res. 31 (9) (2015) 1348-1360.

[33] H. Shi, K. Chen, Z. Shen, J. Wu, X. Dong, L. Zhang, A. Shan, Twin boundary characters established during dynamic recrystallization in a nickel alloy, Mater. Charact. 110 (2015) 52-59.

[34] S. Van Petegem, S. Brandstetter, R. Maass, A.M. Hodge, B.S. El-Dasher, J. Biener, B. Schmitt, C. Borca, H. Van Swygenhoven, On the microstructure of nanoporous gold: an X-ray diffraction study, Nano Lett. 9 (3) (2009) 1158-1163.

[35] E.-J. Gwak, J.-Y. Kim, Weakened flexural strength of nanocrystalline nanoporous gold by grain refinement, Nano Lett. 16 (2016) 2497-2502.

[36] E. Detsi, S. Punzhin, J. Rao, P.R. Onck, J.Th.M. De Hosson, Enhanced strain in functional nanoporous gold with a dual microscopic length scale structure, ACS Nano 6 (5) (2012) 3734-3744.

[37] K. Fisher, Fundamentals of Solidification, 4th revised edition, (1998).

[38] T. Hildebrand, P. Ruesgsegger, A new method for the model-independent assess ment of thickness in three-dimensional images, J. Microsc. 185 (1996) 67-75.

[39] T. Saito, J. Toriwaki, New algorithms for Euclidean distance transformation on an n-dimensional digitized picture with applications, Pattern Recogn. 27 (1994) 1551-1565.

[40] E. Maire, X-ray tomography applied to the characterization of highly porous materials, Annu. Rev. Mater. Res. 42 (2012) 163-178.

[41] D. Legland, I. Arganda-Carreras, P. Andrey, MorphoLibJ: integrated library and plugins for mathematical morphology with ImageJ, Bioinformatics 32 (22) (2016) 3532-3534.

[42] T. Wada, J. Yamada, H. Kato, Preparation of three-dimensional nanoporous Si using dealloying by metallic melt and application as a lithium-ion rechargeable battery negative electrode, J. Power Sources 306 (2016) 8-16.

[43] V.D. Doroeolskii, S.M. Karalnuk, A.V. Koval, Solid solutions in the V-Ti, V-Fe, Fe-Cr and Fe-Ni systems, Metallofizika 41 (1972) 73-77.

[44] D.J. Dyson, B. Holmes, Effect of alloying additions on the lattice parameter of austenite, J. Iron Steel Inst. 208 (1970) 469-474.

[45] R. Mohammadzadeh, M. Mohammadzadeh, Correlation between stacking fault energy and lattice parameter in nanocrystalline $\mathrm{Fe}-\mathrm{Cr}-\mathrm{Ni}$ austenitic stainless steels by atomistic simulation study, Int. J. Model. Simul. 37 (4) (2017) 227-233.

[46] W.B. Liu, S.C. Zhang, N. Li, J.W. Zheng, S.S. An, Y.L. Xing, A general dealloying strategy to nanoporous intermetallics, nanoporous metals with bimodal, and unimodal pore size distributions, Corros. Sci. 58 (2012) 133-138.

[47] C. Lakshmanan, R.N. Viswanath, S.R. Polaki, R. Rajaraman, S. Dash, A.K. Tyagi, Surface area of nanoporous gold: effect on temperature, Electrochim. Acta 182 (2015) 565-572. 
[48] E. Detsi, E. De Jong, A. Zinchenko, Z. Vukovic, I. Vukovic, S. Punzhin, K. Loos, G. ten Brinke, H.A. De Raedt, P.R. Onck, J.T.M. De Hosson, On the specific surface area of nanoporous materials, Acta Mater. 59 (2011) 7488-7497.

[49] Y.H. Tan, J.A. Davis, K. Fujikawa, N.V. Ganesh, A.V. Demchenko, K.J. Stine, Surface area and pore size characteristics of nanoporous gold subjected to thermal, mechanical, or surface modification studied using gas adsorption isotherms, cyclic voltammetry, thermogravimetric analysis, and scanning electron microscopy, J. Mater. Chem. 22 (2012) 6733.

[50] K.F.L. Michielsen, H. De Raedt, J.Th.M. De Hosson, Aspects of mathematical morphology, Advances in Imaging and Electron Physics, vol. 125, 2002, pp. 119-195.

[51] K.R. Mangipudi, V. Radisch, L. Holzer, C.A. Volkert, A FIB-nanotomography method for accurate 3D reconstruction of open nanoporous structures, Ultramicroscopy 163 (2016) 38-47.

[52] Y.-C. Chen-Wiegart, Y. Chu, J. Yi, I. Mcnulty, Q. Shen, P. Voorhees, D. Dunand,
Morphological and topological analysis of coarsened nanoporous gold by x-ray nanotomography, Appl. Phys. Lett. 96 (2010) 1-3.

[53] E. Lilleodden, P. Voorhees, On the topological, morphological, and microstructural characterization of nanoporous metals, MRS Bull. 43 (1) (2018) 20-26.

[54] I.V. Thorat, D.E. Stephenson, N.A. Zacharias, K. Zaghib, J.N. Harb, D.R. Wheeler, Quantifying tortuosity in porous Li-ion battery materials, J. Power Sources 188 (2009) 592-596.

[55] Y. Xue, J. Markmann, H. Duan, J. Weissmuller, P. Hubert, Switchable imbibition in nanoporous gold, Nat. Commun. 5 (2014) 1-8.

[56] J. Bear, Dynamics of Fluids in Porous Media, Chap 4 : The fundamental fluid transport equations in porous media, (1972), pp. 65-118.

[57] D.A.G. Bruggeman, Berechnung verschiedener physikalischer Konstanten von heterogenen Substanzen, Ann. Phys. 24 (1935) 636. 